\title{
MORPHOMETRY AND MERISTICS OF LONGNOSE SEAHORSE, HIPPOCAMPUS TRIMACULATUS (ACTINOPTERYGII: SYNGNATHIDAE), FROM KERALA, SOUTH-WEST COAST OF INDIA
}

\author{
Appukuttannair BIJUKUMAR ${ }^{1 *}$, Kurian M. ABRAHAM ${ }^{2}$, and Devarajan SOUMYA ${ }^{1}$ \\ ${ }^{1}$ Department of Aquatic Biology and Fisheries, University of Kerala, Thiruvananthapuram, Kerala, India \\ ${ }^{2}$ Postgraduate and Research Department of Zoology, Mar Thoma College, \\ Tiruvalla 689 103, Kerala, India
}

\begin{abstract}
Bijukumar A., Abraham K.M., Soumya D. 2008. Morphometry and meristics of longnose seahorse, Hippocampus trimaculatus (Actinopterygii: Syngnathidae), from Kerala, south-west coast of India. Acta Ichthyol. Piscat. 38 (2): 149-155.
\end{abstract}

Background. The longnose seahorse, Hippocampus trimaculatus Leach, 1814, included in the Red List of Threatened Species is the most common and least studied seahorse species along the south-west coast of India. Practically no information is available on numerical taxonomy and sexual dimorphism of $H$. trimaculatus from India. The purpose of the reported study is to describe the morphometry and meristics of $H$. trimaculatus occurring along Kerala, south-west coast of India.

Materials and Methods. A total of 45 specimens of H. trimaculatus, represented by 25 males and 20 females, obtained from trawl by-catch, were studied following standard morphometric and meristics procedures. Statistical data analyses include Student's $t$-test, Mann-Whitney $U$ test, and Principal Component Analysis to describe the sexual dimorphism of the species.

Results. Male $H$. trimaculatus are longer than females, with relatively longer tails. The mean values of head depth, snout depth, trunk depth, trunk width, dorsal fin base length, and pectoral fin base length are higher in males, while head length, snout length, coronet height, and trunk length are higher in females. Trunk length and snout depth are the two principal components that determine sexual dimorphism in H. trimaculatus.

Conclusion. The numerical taxonomy of $H$. trimaculatus from Indian coastal waters is reported for the first time. The study shows that sexual dimorphism in H. trimaculatus is reflected in differing morphometric characters between the sexes.

Keywords: Syngnathidae, longnose seahorse, three-spotted seahorse, low-crowned seahorse, morphology, conservation, sexual dimorphism

\section{INTRODUCTION}

Seahorses are unique among bony fishes, primarily due to their unique morphology and biological characteristics, in particular their highly derived reproductive biology with male parental care (Wilson et al. 2001). All seahorses belong to the genus Hippocampus Rafinesque, 1810 and are monomorphic. Along with pipefishes, pipehorses, and seadragons, they compose the family Syngnathidae, within the order Gasterosteiformes (cf. Nelson 1994). Seahorses, representing the subfamily Hippocampinae, are characterized by a fully enclosed brood pouch with a small opening for the incubation of eggs, vestigial caudal fin, and a prehensile tail (Lourie et al. 1999b, 2004).

Seahorse populations throughout the world have continuously been declining due to the traditional medicine trade, overfishing, destructive fishing methods such as trawling and dynamite fishing, marine aquarium trade and curio trade, as well as habitat destruction and pollution (Lourie et al. 2004). As seahorse populations are declining worldwide, out of the 33 species described, ten seahorse species were listed as 'Vulnerable' or 'Endangered' in the 2007 IUCN Red List of Threatened Species (Anonymous 2007), while others are listed as 'Data Deficient' reflecting a substantial gap in knowledge. The entire genus Hippocampus has been added to Appendix II of Convention on International Trade in Endangered Species of Wild Fauna and Flora (Anonymous 2008). Until the inclusion of seahorses under the purview of Schedule I of Indian Wildlife (Protection) Act (IWPA) in 2001, there existed an organized trade and targeted fish-

\footnotetext{
* Correspondence: Dr. A. Bijukumar, Department of Aquatic Biology and Fisheries, University of Kerala, Thiruvananthapuram 695 581, Kerala, India, phone+91 094472 16157, fax: +91 471 22722151, e-mail: abiju@rediffmail.com
} 
ing for seahorses (Marichamy et al. 1993, Anil et al. 1999, Salin et al. 2005) and India was one of the leading seahorse exporters (Vincent 1996), in particular for dried seahorses (Vincent 1996, Sreepada et al. 2002). The annual export from the country during the 1990s was to the tune of about $3.6 \mathrm{t}$, comprising about 1.3 million sea horses.

The escalating trade and worldwide decline of seahorse populations reiterate the need to resolve seahorse taxonomy. The longnose seahorse, Hippocampus trimaculatus Leach, 1814, (known also as three-spotted seahorse or low-crowned seahorse) is distributed in Australia, Cambodia, China (Hong Kong SAR and Province of Taiwan), France (Tahiti), India, Indonesia, Japan, Malaysia, Myanmar, Philippines, Singapore, Thailand, and Vietnam (Lourie et al. 2004). Clear species identification will make it easier to modify fishing practices appropriately, design protective marine reserves, assess captive breeding potential for seahorses, and develop protective legislation (Lourie et al. 1999a, Anonymous 2008). The sharp, hook-like cheek and eye spines, low coronet, narrow head, and absence of nose spine are the main taxonomic characters to identify the longnose seahorse, Hippocampus trimaculatus (cf. Lourie et al. 1999b).

The biodiversity surveys done by the first author on the by-catch of shrimp trawlers of Kerala coast from January 2004 to February 2007 yielded only 45 specimens of $H$. trimaculatus, indicating the decline in number of seahorses in the south-west coast of India (A. Bijukumar, unpublished data). In the absence of targeted collections, trawling is the major threat for seahorses in Indian coastal waters. Shrimp trawlers pose great threat to seahorse pop- ulations (Meeuwig et al. 2006) and they are more vulnerable than many other groups of animals to this fishing method (Stobutzki et al. 2001).

Morphometrics and meristics have been commonly used to distinguish the species taxonomically, to identify stocks of fish, and to separate different morphotypes (Lourie et al. 1999a, Doherty and McCarthy 2004, Jayasankar et al. 2004). Listed as vulnerable (VU A4cd) in the Red List of Threatened Species and included under Schedule I of IWPA, H. trimaculatus is a common seahorse species along south-west and south-east coasts of India and the morphometry and meristics of $H$. trimaculatus have not so far been determined from Indian waters. The taxonomic description of $H$. trimaculatus is available in the taxonomic guides of seahorses (Lourie et al. 1999b, 2004), and morphometry of this species was reported by Lourie et al. (1999a) based on specimens collected from Vietnam. This paper describes the morphometry and meristics of H. trimaculatus from Kerala, south-west coast of India and delineates the principal morphological characters that elucidate the sexual dimorphism.

\section{MATERIALS AND METHODS}

Specimens of Hippocampus trimaculatus (Fig. 1) were obtained for the study from the trawl by-catch of Sakthikulangara and Neendakara fishing harbours (lat $08^{\circ} 30^{\circ} \mathrm{N}$, long $76^{\circ} 53.3^{\circ} \mathrm{E}$ ), Kollam district (lat $9^{\circ} 28^{\circ} \mathrm{N}$ to $8^{\circ} 45^{\circ} \mathrm{N}$, long $76^{\circ} 28^{\circ} \mathrm{E}$ to $77^{\circ} 17^{\circ} \mathrm{E}$ ), Kerala state, southwest coast of India from January 2004 to February 2008.

Morphometric measurements (Fig. 2) were done based on 25 males and 20 females, using the methods of measuring seahorses proposed by Lourie (2003). The following morphometric measurements were taken using dial callipers

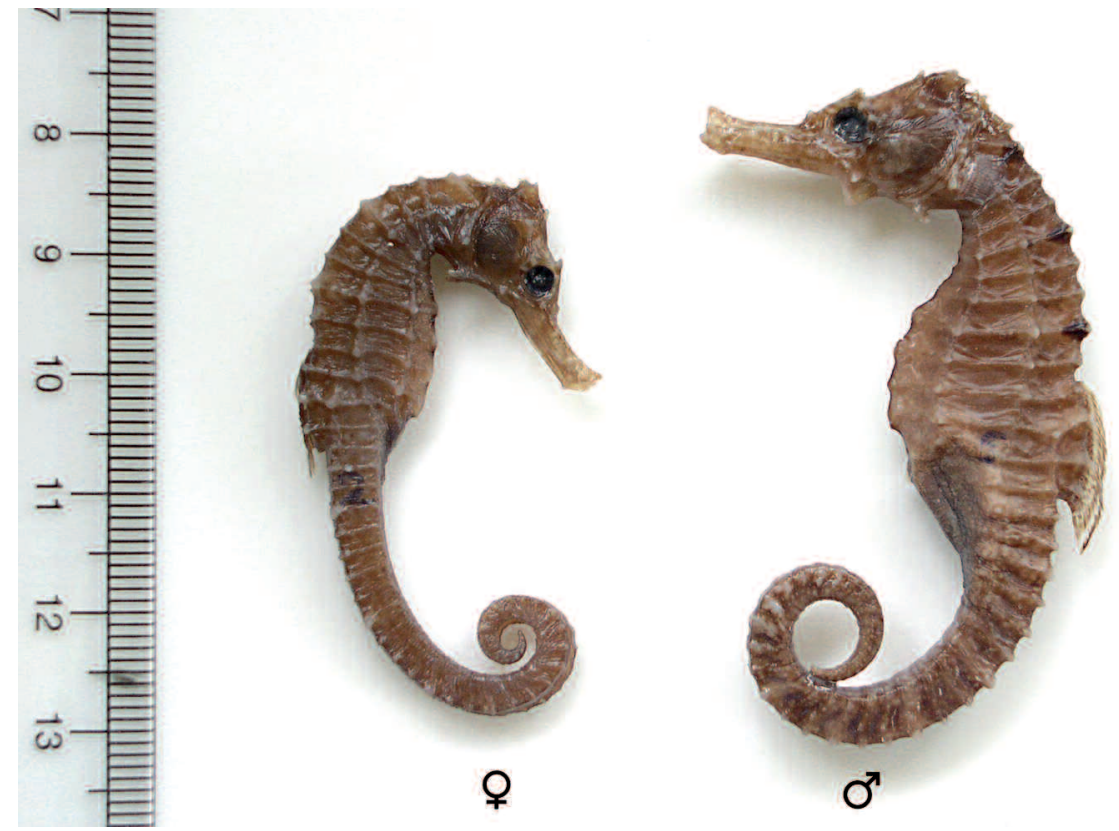

Fig. 1. Male (right) and female (left) of Hippocampus trimaculatus 


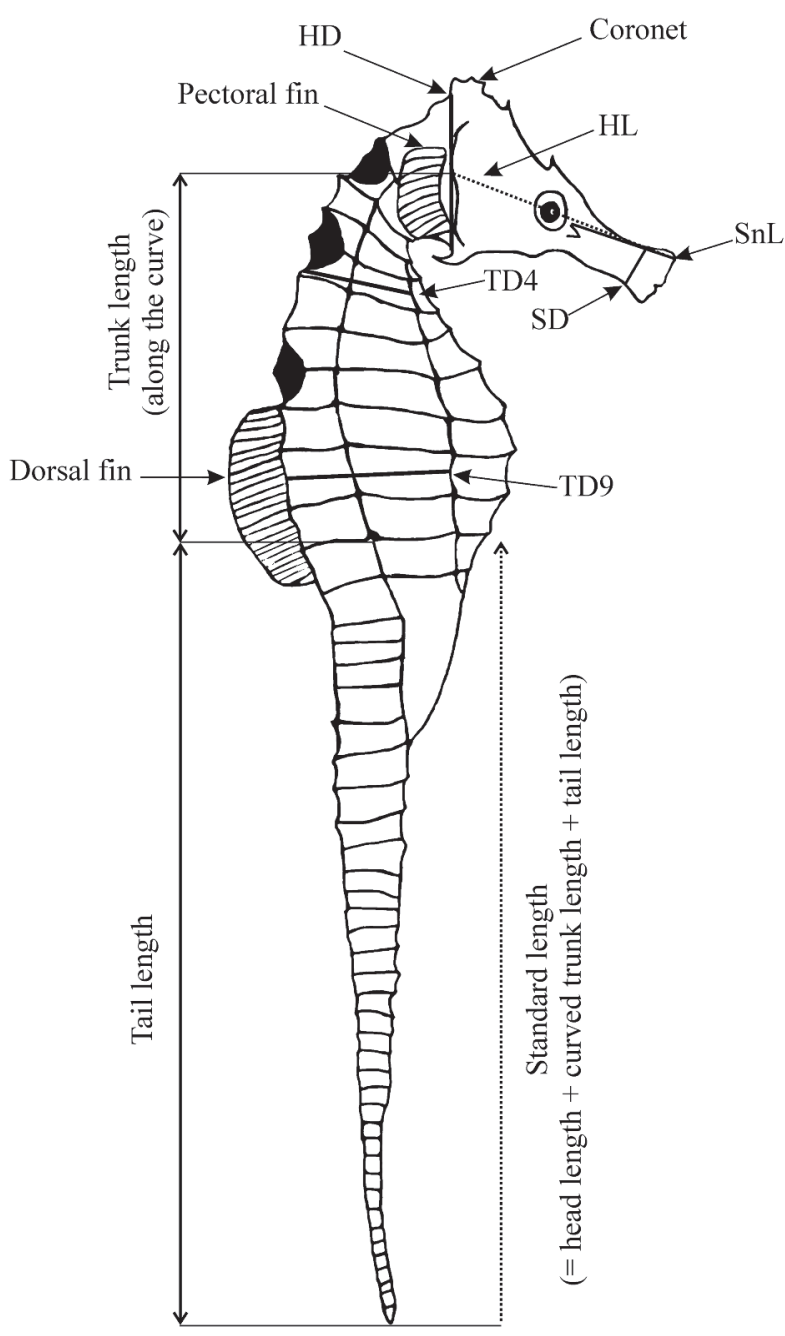

Fig. 2. Diagram of morphometric measurements of Hippocampus trimaculatus

to the nearest $0.1 \mathrm{~mm}$, on the right side of the seahorse: (i) standard length (SL); (ii) trunk length (TrL); (iii) tail length (TaL); (iv) coronet height $(\mathrm{CH})$; (v) head length (HL); (vi) snout length (SnL); (vii) snout depth (SD); (viii) head depth (HD); (ix) trunk depth between the 4th and 5th trunk ring (TD4); (x) trunk width between the 9th and 10th trunk ring (TW9); (xi) length of dorsal fin base (DL); (xii) length of pectoral fin base (PL).

The meristic characters determined included: number of trunk rings, number of tail rings, number of pectoral fin rays, and number of dorsal fin rays. The fin rays, trunk rings, and tail rings were counted under a binocular stereo zoom microscope. The number of external raised bony rings that encircle the body and tail were considered as trunk and tail rings, respectively. The indices (Lourie 2003) selected for the study were: (i) spikiness index, for the first few spines on dorsal surface of tail (ignoring larger ones where spines run in a series) $[1=$ sum of spine lengths on left + right side $\leq 1 / 4$ dorsal width of that tail segment, $2=$ length of spines $>1 / 4$ but $\leq 3 / 4$ dorsal width, 3 = length of spines $>3 / 4$ dorsal width]; (ii) Coronet height index, a semi-quantitative measure of the overall height of the coronet in relation to the arch of the trunk; (iii) Keel index, a semi-quantitative measure of the depth of the body ventral to the ventral trunk ridge ( $1=$ no ventral keel, $2=$ ventral keel $<1 \mathrm{~mm}$ deep, $3=$ ventral keel $1-3$ $\mathrm{mm}$ deep, $4=$ ventral keel $>3 \mathrm{~mm}$ deep]; and (iv) chin shape index, a qualitative description of the arrangement and form of the cheek spines as viewed from the ventral surface of the head.

Data were analyzed using the computer software Statistical Package for Social Sciences (SPSS). Mean morphometric and median meristic parameters were compared between males and females using Student's $t$-test and non-parametric Mann-Whitney $U$ test respectively. To identify the characters leading to the morphological differences between males and females, Principal Component Analysis (PCA) was employed in which factor loadings based on Eigen values were used to determine the morphometric factors. The PCA was executed after $\log$ transformation of the data. For all statistical evaluations, a two-tailed probability of value $<0.05$ was considered significant.

Table 1

Mean morphometric characters $(\mathrm{mm})$ (mean \pm standard deviation) of Hippocampus trimaculatus; $t$-values are based on Student's $t$-test

\begin{tabular}{|c|c|c|c|c|c|}
\hline Character & Male & Female & Total & $t$ value comparing sexes & Mean as $\%$ of SL \\
\hline Standard length & $110.40 \pm 3.16$ & $108.50 \pm 5.80$ & $109.20 \pm 4.68$ & $0.520(0.607)$ & - \\
\hline Trunk length & $22.00 \pm 3.16$ & $23.25 \pm 3.43$ & $22.36 \pm 3.24$ & $1.032(0.309)$ & 20.45 \\
\hline Tail length & $69.00 \pm 2.47$ & $66.00 \pm 1.05$ & $67.46 \pm 2.93$ & $0.001(0.994)$ & 61.78 \\
\hline Head length & $16.60 \pm 2.78$ & $19.25 \pm 1.32$ & $17.36 \pm 2.72$ & $2.865(0.0071)^{\text {*** }}$ & 15.90 \\
\hline Snout length & $8.20 \pm 0.76$ & $9.00 \pm 0.00$ & $8.43 \pm 0.74$ & $3.283(0.0024)^{* *}$ & 7.72 \\
\hline Coronet height & $2.53 \pm 0.62$ & $2.70 \pm 0.86$ & $2.58 \pm 0.89$ & $2.821(0.0105)^{*}$ & 2.36 \\
\hline Head depth & $8.25 \pm 0.26$ & $7.20 \pm 1.19$ & $7.50 \pm 1.12$ & $2.740(0.0104)^{*}$ & 6.88 \\
\hline Snout depth & $3.00 \pm 1.05$ & $2.50 \pm 0.32$ & $2.64 \pm 0.65$ & $2.171(0.0371)^{*}$ & 2.42 \\
\hline Trunk depth between rings $4 / 5$ & $8.40 \pm 0.75$ & $8.25 \pm 0.26$ & $8.36 \pm 0.65$ & $0.613(0.544)$ & 7.66 \\
\hline Trunk width & $12.20 \pm 1.76$ & $10.75 \pm 1.32$ & $11.79 \pm 1.75$ & $2.352(0.0254)^{*}$ & 10.80 \\
\hline Dorsal fin base length & $8.70 \pm 1.35$ & $8.50 \pm 0.53$ & $8.60 \pm 1.23$ & $1.801(0.0971)$ & 7.90 \\
\hline Pectoral fin base length & $3.90 \pm 0.20$ & $3.75 \pm 0.26$ & $3.86 \pm 0.23$ & $1.807(0.098)$ & 3.53 \\
\hline
\end{tabular}

${ }^{*} P<0.05 ;{ }^{* *} P<0.01 ; P$ values are given in parentheses. 


\section{RESULTS}

Description. Coronet very low, in line with arch of neck, visible as five tiny backwardly directed spines. Head narrow. Nose spine absent. No spines on junctions of body ridges. Very sharp hook-like cheek spine, bordering throat at base of cleithral ring and eye spine above orbit on each side. Two trunk rings and one tail ring supporting dorsal fin. In live specimens golden orange or brown; majority of individuals collected with large dark spots on dorso-lateral surface of first-, fourth-, and seventh trunk rings. Spots visible clearly in light coloured specimens rather than in dark coloured, and in males rather than in females (Fig. 1). Out of 25 male and 20 female specimens studied, black spots were indistinct in 6 males and 11 females. Rarely caught in trawl nets and landed as by-catch in the south-west coast of India. No organized fishing and trade in Kerala.

Dorsal fin rays $18-21$ (median $=20)$; pectoral fin rays 16-19 (17); anal fin rays 4; trunk rings 11; tail rings 39-40 (39); spikiness index 1; coronet height index 1; keel depth index 3; chin shape index 3.

Morphometry. The mean morphometric characters of Hippocampus trimaculatus are given in Table 1. The mean standard length (SL) of the studied population of $H$. trimaculatus was $109.20 \pm 4.68 \mathrm{~mm}$. The mean values of trunk length $(\mathrm{TrL})(22.36 \pm 3.24 \mathrm{~mm})$, tail length $(\mathrm{TaL})$ $(67.46 \pm 2.93 \mathrm{~mm})$, head length (HL) $(17.36 \pm 2.72 \mathrm{~mm})$, and snout length $(\mathrm{SnL})(8.43 \pm 0.74 \mathrm{~mm})$, constituted $20.45 \%, 61.78 \%, 15.90 \%$, and $7.72 \%$ of the SL, respectively (Table 1). The mean coronet height $(2.58 \pm 0.89 \mathrm{~mm})$ was $2.36 \%$ of the SL, while head depth $(7.50 \pm 1.12 \mathrm{~mm})$ was $6.88 \%$ of the SL. The mean snout depth $(2.64 \pm 0.65 \mathrm{~mm})$ and mean trunk depth between fourth and fifth rings (8.36 \pm $0.65 \mathrm{~mm}$ ) were $2.46 \%$ and $7.66 \%$ of the SL, respectively. The mean trunk width $(11.79 \pm 1.75 \mathrm{~mm})$ was $10.80 \%$ of the SL. The mean dorsal fin base length $(8.60 \pm 1.23 \mathrm{~mm})$ and mean pectoral fin base length $(3.86 \pm 0.23 \mathrm{~mm})$ were $7.9 \%$ and $3.53 \%$ of the SL, respectively (Table 1 ).
Following a Student's $t$-test, morphometric characters such as head length, snout length, coronet height, head depth, snout depth, and trunk width showed significant difference between male and female specimens studied (Table 1).

The standard length of the 25 male specimens selected for the study varied from 99 to $122 \mathrm{~mm}(110.40 \pm 3.16$ $\mathrm{mm})$, whereas in females the range was from 103 to 114 $\mathrm{mm}(108.5 \pm 5.8 \mathrm{~mm})$. The average trunk length was 22 $\mathrm{mm}$ in male and $23.25 \mathrm{~mm}$ in females. The mean tail length was higher in males than in female specimens $(66.00 \pm 1.05 \mathrm{~mm})$. In males the mean head length was $16.60 \pm 2.78 \mathrm{~mm}$, whereas it was $19.25 \pm 1.32 \mathrm{~mm}$ in females. The HL/SnL ratio was 2.1 (1.9-2.4). The mean snout length also recorded higher values in females ( 9 $\mathrm{mm})$ than in males $(8.2 \mathrm{~mm})$. Female specimens recorded higher mean coronet height $(2.7 \mathrm{~mm})$ than males $(2.53$ $\mathrm{mm})$. The mean head depth and the mean snout depth of males $(8.25 \pm 0.26 \mathrm{~mm}$ and $3.0 \pm 1.05 \mathrm{~mm}$, respectively) were higher than that of females $(7.2 \pm 1.19 \mathrm{~mm}$ and 2.50 $\pm 0.32 \mathrm{~mm}$, respectively). The mean trunk depth between 4-5 rings and the mean trunk width were higher in males $(8.4 \pm 0.75 \mathrm{~mm}$ and $12.2 \pm 1.76 \mathrm{~mm}$, respectively) than those in females $(8.25 \pm 0.26 \mathrm{~mm}$ and $10.75 \pm 1.32 \mathrm{~mm}$, respectively). Likewise the mean dorsal fin base length and the pectoral fin base length were slightly higher in male seahorses.

The mean percentage of different parameters of male and female $H$. trimaculatus is given in Table 2. As percentage of SL, the mean trunk length and head length were higher in females, while the mean tail length recorded higher values in males. Snout length and head depth $(\% \mathrm{HL})$ were higher for males. Coronet height, as percentage of head depth was higher for females compared to that of males. As percentage of trunk length, trunk depth and trunk width recorded higher values in males.

Meristic Characters. The meristic characters of $H$. trimaculatus are given in Table 3. The number of trunk rings in H. trimaculatus was 11 in both males and females.

Table 2

Relative values of individual characters (mean \pm standard deviation) of male and female Hippocampus trimaculatus

\begin{tabular}{lccc}
\hline Character & Male & Female & Total Population \\
\hline Trunk length (\% of SL) & $19.93 \pm 1.36$ & $21.43 \pm 0.68$ & $20.69 \pm 1.18$ \\
Tail length (\% of SL) & $62.50 \pm 3.25$ & $60.83 \pm 2.69$ & $61.68 \pm 3.19$ \\
Head length (\% of SL) & $15.04 \pm 1.04$ & $17.74 \pm 0.47$ & $16.32 \pm 0.97$ \\
Snout length (\% of HL) & $49.40 \pm 2.06$ & $46.75 \pm 1.36$ & $48.56 \pm 1.86$ \\
Coronet height (\% of HD) & $30.67 \pm 2.98$ & $37.50 \pm 2.28$ & $34.43 \pm 2.78$ \\
Head depth (\% of HL) & $49.70 \pm 1.35$ & $37.40 \pm 1.68$ & $43.21 \pm 2.18$ \\
Snout depth (\% of SnL) & $36.59 \pm 1.11$ & $27.78 \pm 1.09$ & $31.36 \pm 1.59$ \\
Trunk depth between rings 4/5 (\% of TrL) & $38.18 \pm 1.25$ & $35.48 \pm 1.55$ & $37.38 \pm 2.05$ \\
Trunk width (\% of TrL) & $55.45 \pm 2.32$ & $46.24 \pm 1.69$ & $52.72 \pm 2.19$ \\
Dorsal fin base length $(\%$ of TrL) & $39.55 \pm 1.56$ & $36.56 \pm 2.08$ & $38.94 \pm 2.58$ \\
Pectoral fin base length $\%$ of TrL) & $17.73 \pm 0.68$ & $16.13 \pm 0.88$ & $16.25 \pm 1.38$ \\
\hline
\end{tabular}

$\mathrm{SL}=$ standard length; $\mathrm{HL}=$ head length; $\mathrm{SnL}=$ snout length; $\mathrm{TrL}=$ trunk length. 
In males the number of tail rings was 41 , whereas in females it was 39. Similarly, median values of pectoral and dorsal fin rays were higher in male fishes by one count. Results of Mann-Whitney $U$ test showed that the number of tail rings, pectoral fin rays, and dorsal fin rays varied significantly between male and female $H$. trimaculatus.

Principal Component Analysis. Principal Component Analysis (PCA), used to elucidate the factors contributing to sexual dimorphism in Hippocampus trimaculatus, showed that several morphometric parameters play an important role in differentiating male and female specimens. PCA was applied to log-transformed morphometric and meristic characters of male and female specimens. First principal component (PC 1) with $70.32 \% \mathrm{CV}$ resulted in both positive and negative factor loadings, indicating size and shape variation between males and females (Table 4). High factor loading values were obtained for different morphometric parameters in principal component 1 where as principal component 2 showed all positive but low factor loading values (Fig. 3). Trunk length, head depth, total length, standard length, and head length were the characteristics most highly correlated with PC1. Out of these, trunk length was found to be the most important character, which determines sexual dimorphism.

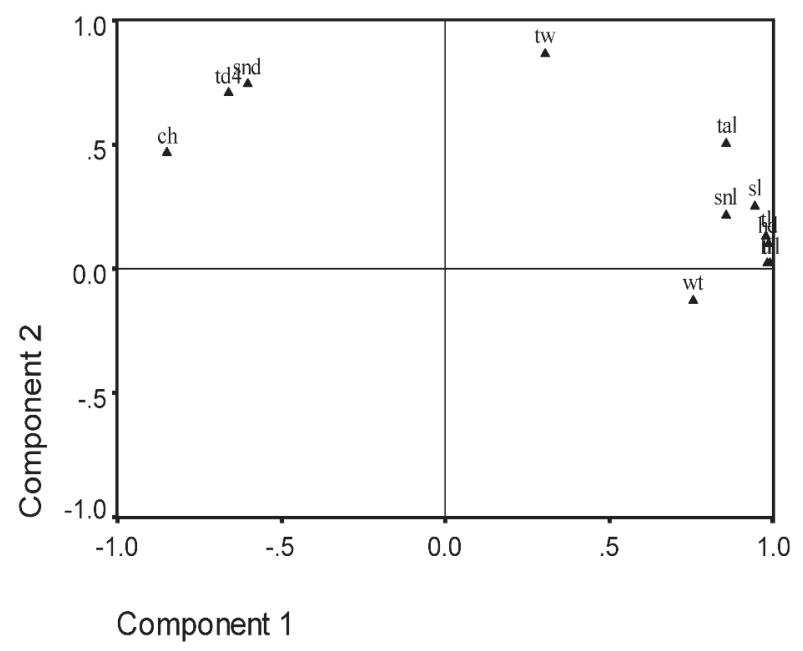

Fig. 3. Factor loading component plot of principal component analysis of Hippocampus trimaculatus

Principal component 2 (PC2) described $20.44 \%$ of the variance, with snout depth, coronet height, and tail length being most highly correlated with PC2. Snout depth was found to be principal component 2, which distinguishes male from female. Trunk length was higher in females, while snout depth was higher in males (Table 1). The first two principal components accounted for $90.76 \%$ of the total variance in male and female specimens of $H$. trimaculatus.

\section{DISCUSSION}

The longnose seahorse, Hippocampus trimaculatus Leach, is a non-migratory species, inhabiting gravel or sand bottoms of shallow seas. Until the inclusion of $H$. trimaculatus in Schedule I of the Wildlife (Protection) Act of India, which prohibits collection and trade of seahorses, the seahorse trade was very much prevalent in India. At present, the trade of seahorses continues illegally, and seahorses are primarily sold as powdered form. Although the current state of $H$. trimaculatus population in Kerala is unknown, the population seems to be in the process of declining, as fishermen have reported the decline of seahorses in their catches (A. Bijukumar, unpublished data). There is hardly any information on seahorse taxonomy and biometry from the coastal waters of India. Precise taxonomy of the seahorses is required to identify them in field, and to record catch statistics, especially the by-catch of shrimp trawlers that yield high numbers of seahorses (Salin et al. 2005). All the specimens for this report were obtained from by-catch of shrimp trawlers operating from Kerala, south-west coast of India.

One of the features of $H$. trimaculatus is the characteristic "three spots" on their dorsolateral trunk surface. However, this cannot be always used as the taxonomic character to distinguish this species because it is not observed in all the specimens. The spots were not obvious in 6 male and 11 female specimens studied. The spots were clear in light coloured specimens and more pronounced in males. According to Lourie et al. (1999b), variation in overall body shape, relative snout length, coronet height, number of tail rings, chin shape and degree of development of body and tail spines are sufficient to separate the specimens of sea horses in general. As reported by Lourie et al. (1999a), based on the study of $H$. trimaculatus populations from Vietnam, low coronet, which is visible as 5 tiny points and sharp hook-like cheek, and eye spines can be considered as a taxonomic character in the field for the identification of H. trimaculatus populations in Kerala.

In general, the taxonomic characters of $H$. trimaculatus in the coastal waters of southwest coast of India are in corroboration with the published works (Lourie et al. 1999a, b, 2004). The mean SL (109 mm), range of HL/SnL ratio (1.9-2.4), number of trunk rings (11), number of tail rings (39-41), number of dorsal fin rays (19-20), and the indices on spikiness (1), coronet height (1), keel depth (3), and chin shape (3) of the H. trimaculatus population in Vietnam (Lourie et al. 1999a) and Kerala coast were in total agreement.

The morphometric and meristic characters differed between males and females. Male specimens were found to be longer than females, with longer tails. Males of H. trimaculatus were reported to be longer by workers of south-east Asia (Lourie et al. 1999a, Choo and Liew 2003, Meeuwig et al. 2006). The occurrence of sexual dimorphism in seahorse length may be due to sex-specific differences in mortality rates (Foster and Vincent 2004). The longer tail in males may enable them to support a large caudal brood pouch or may give males an advantage in the tail-wrestling exhibited during mating competition (Vincent 1990).

The mean head depth, snout depth, trunk depth, trunk width, dorsal fin base length, and pectoral fin base length 
Table 3

Meristic characters in male and female Hippocampus trimaculatus

\begin{tabular}{|c|c|c|c|c|c|c|}
\hline \multirow{2}{*}{ Character } & \multicolumn{2}{|c|}{ Male } & \multicolumn{2}{|c|}{ Female } & \multirow{2}{*}{$\frac{\text { Total }}{\bar{x} \pm s}$} & \multirow{2}{*}{$U$} \\
\hline & $\bar{x} \pm s$ & Median & $\bar{x} \pm s$ & Median & & \\
\hline Trunk rings & $11.04 \pm 0.14$ & 11.00 & $11.05 \pm 0.05$ & 11.00 & $11.04 \pm 0.12$ & 87.501 \\
\hline Tail rings & $42.20 \pm 0.41$ & 41.00 & $39.00 \pm 1.05$ & 39.00 & $39.60 \pm 0.34$ & $75.000^{*}$ \\
\hline Pectoral fin rays & $16.80 \pm 0.76$ & 17.00 & $16.00 \pm 0.00$ & 16.00 & $16.57 \pm 0.74$ & $50.000^{* *}$ \\
\hline Dorsal fin rays & $19.60 \pm 0.82$ & 20.00 & $19.00 \pm 0.00$ & 19.00 & $19.43 \pm 0.74$ & $50.000^{* *}$ \\
\hline
\end{tabular}

${ }^{*} P<0.05 ;{ }^{* *} P<0.01 ; \bar{x}=$ mean; $s=$ standard deviation; $U=$ Mann-Whitney $U$ value.

Table 4

Principal Component Analysis of transformed morphometric variables for gender in Hippocampus trimaculatus

\begin{tabular}{lcc}
\hline Variable & Principal component 1 & Principal component 2 \\
\hline Standard length & 0.947 & 0.255 \\
Weight & 0.758 & -0.125 \\
Trunk length & 0.992 & 0.023 \\
Tail length & 0.858 & 0.508 \\
Head length & 0.984 & 0.024 \\
Snout length & 0.856 & 0.220 \\
Coronet height & -0.848 & 0.467 \\
Head depth & 0.989 & 0.105 \\
Snout depth & -0.602 & 0.746 \\
Trunk depth between rings $4 / 5$ & -0.660 & 0.711 \\
Eigen value & 8.44 & 2.45 \\
\% of variance & 70.32 & 20.44 \\
Cumulative \% variance & 70.32 & 90.76 \\
\hline
\end{tabular}

were also higher for males. The mean values of head length, snout length, coronet height, and trunk length were higher in females. Males possess shorter and thicker snouts, and it has been suggested that this is related to certain behaviour; they use their snouts to snap at competitors (Vincent 1996). Differences in foraging might also contribute to the observed difference in snout shape (Shine 1991). Longer trunk in females is a common feature of seahorses (Foster and Vincent 2004).

Trunk length and snout depth were identified as the principal morphometric features to distinguish males and females; the trunk length was significantly higher in females whereas snout depth was higher in male seahorses. These factors could be used to distinguish male and female specimens. In PCA, any component having all coefficients (component loadings) of the same sign was indicative of the size variation, whereas any component having both positive and negative coefficients was indicative of shape variation (Jolicoeur and Mosimann 1960). The coefficients obtained during the present study were both positive and negative. Therefore it can be assumed that the males and females of $H$. trimaculatus could be distinguished by shape rather than size variation, as suggested by Vincent (1996).

\section{REFERENCES}

Anil M.K., Kakati V.S., Ganga U., Zacharia S. 1999. Larval rearing of sea horse Hippocampus kuda under laboratory conditions. Marine Fisheries Information Service Technical and Education Series, Central Marine Fisheries Research Institute, Cochin, India No. 162: 23-25.

Anonymous 2007. IUCN Red List of Threatened Species 2007. IUCN, Gland, Switzerland. http://www.iucnredlist.org (Assessed on 14 June 2008.) 
Anonymous 2008. Convention on international trade in endangered species of fauna and flora. Appendices I, II and III valid from 1 July 2008. Geneva, Switzerland. http://www.cites.org.

Choo C.K., Liew H.C. 2003. Spatial distribution, substrate assemblages and size composition of sea horses (Family Syngnathidae) in the coastal waters of Peninsular Malaysia. Journal of Marine Biology Association of the United Kingdom 83: 271-276.

Doherty D., McCarthy T.K. 2004. Morphometric and meristic characteristics analyses of two western Irish populations of Arctic Char, Salvelinus alpinus (L.). Proceedings of the Royal Irish Academy B 104: 75-85.

Foster S.J., Vincent A.C.J. 2004. Life history and ecology of seahorses: implications for conservation and management. Journal of Fish Biology 65: 1-61.

Jayasankar P., Thomas P.C., Paulton M.P., Mathew J. 2004. Morphometric and genetic analyzes of Indian mackerel (Rastrelliger kanagurta) from peninsular India. Asian Fisheries Science 17: 201-215.

Jolicoeur P., Mosimann J.E. 1960. Size and shape variation in the painted turtle: a principal component analysis. Growth $\mathbf{2 4}$ : 691-699.

Lourie S.A. 2003. Measuring seahorses. Project Seahorse Technical Report No. 4, Version 1.0. Project Seahorse, Fisheries Centre, University of British Columbia, Canada.

Lourie S.A., Foster S.J., Cooper E.W.T., Vincent A.C.J. 2004. A Guide to the identification of seahorses. Project Seahorse and TRAFFIC North America, University of British Columbia and World Wildlife Fund, Canada.

Lourie S.A., Pritchard J.C., Casey S.P., Truong S.K., Hall H.J., Vincent A.C.J. 1999a. The taxonomy of Vietnam's exploited seahorses (Family Syngnathidae). Biological Journal of the Linnaean Society 66: 231-256.

Lourie S.A., Vincent A.C.J., Hall H.J. 1999b. Seahorses: an identification guide to the world's species and their conservation. Project Seahorse, London, U.K.

Marichamy R., Lipton A.P., Ganapathy A., Ramalingam J.R. 1993. Large scale exploitation of sea horse (Hippocampus kuda) along the Palk Bay Coast of Tamil Nadu. Marine Fisheries Information Service Technical and Education Series, Central Marine Fisheries Research Institute, Cochin, India No. 119: 17-20.

Meeuwig J.J., Hoang D.H., Ky T.S., Job S.D., Vincent A.C.J. 2006. Quantifying non-target seahorse fisheries in central Vietnam. Fisheries Research 81: 149-157.

Nelson J.S. 1994. Fishes of the world. (3rd Ed.). John Wiley and Sons, New York.

Salin K.R., Yohannan T.M., Mohanakumaran Nair C. 2005. Fisheries and trade of seahorses, Hippocampus spp. in Southern India. Fisheries Management and Ecology 12: 269-273.

Shine R. 1991. Intersexual dietary divergence and the evolution of sexual dimorphism in snakes. American Naturalist 138: 103-122.

Sreepada R.A., Desai U.M., Naik S. 2002. The plight of Indian sea horses: Need for conservation and management. Current Science 82: 377-378.

Stobutzki I.C., Miller M.J., Brewer D.T. 2001. Sustainability of fishery bycatch: a process for assessing highly diverse and numerous bycatch. Environmental Conservation 28: 167-181.

Vincent A.C.J. 1990. Reproductive ecology of seahorses. PhD Thesis, Cambridge University, Cambridge, UK.

Vincent A.C.J. 1996. The international trade in seahorses. TRAFFIC International, Cambridge.

Wilson A.B., Vincent A., Ahnesjö I., Meyer A. 2001. Male pregnancy in seahorses and pipefishes (family Syngnathidae): Rapid diversification of paternal brood pouch morphology inferred from a molecular phylogeny. Journal of Heredity 92: 159-166.

Received: 10 August 2008

Accepted: 22 November 2008

Published electronically: 15 December 2008 